\title{
Randomized controlled trial of a nursing intervention to reduce emergency department revisits
}

\author{
Sylvie Cossette, $\mathrm{RN}, \mathrm{PhD}^{*}$; Alain Vadeboncoeur, $\mathrm{MD}^{\dagger}$; Nancy Frasure-Smith, $\mathrm{PhD}^{\ddagger}$; \\ Jane McCusker, MD, DrPH${ }^{\S}$; Danielle Perreault, RN, BSc ${ }^{\dagger}$; Marie-Claude Guertin, $\mathrm{PhD}^{\|}$
}

\section{ABSTRACT}

Objective: To determine whether a nursing intervention delivered at emergency department (ED) discharge would reduce $E D$ revisits.

Method: A randomized study was conducted in the ED of a tertiary cardiac hospital in Montreal, Quebec. Between November 2006 and March 2010, 3,795 patients were assessed for eligibility based on two risk factors for ED revisits ( $\geq 1$ ED visit in the past year and $\geq 6$ medications); 132 were randomized to the experimental group (EG) and 133 to the control group (CG). The intervention included one nurse-patient meeting before leaving the ED, with two additional telephone contacts over the next 2 weeks. The primary outcome was time to ED revisits within 30 days after discharge. Secondary outcomes included time to ED revisits over 90, 180, and 365 days and hospitalizations over 30, 90, 180 , and 365 days.

Results: A planned interim analysis that stopped the study with half of the planned sample showed that the time to ED revisits was similar in both groups at 30 days $(p=0.81$; revisits: $18.2 \%$ in $E G, 19.6 \%$ in CG), 90 days ( $p=0.44$ ), 180 days $(p=0.98)$, and 365 days ( $p=0.75)$. The only difference identified was a lower hospitalization proportion at 180 days in the EG group (13.6\% v. $24.1 \% ; p=0.038$ ).

Conclusions: These findings are consistent with previous research showing that few ED-based interventions are successful in reducing ED returns. Factors other than those targeted by the intervention, including an improvement in usual care, may explain the findings.

\section{RÉSUMÉ}

Objectif: L'étude visait à déterminer si une intervention en soins infirmiers, appliquée au moment du congé du service des urgences (SU) permettrait de réduire le nombre de reconsultations à ce même service.
Méthode: Une étude à répartition aléatoire a été menée au SU d'un hôpital de soins tertiaires en cardiologie, à Montréal. De novembre 2006 à mars 2010, 3795 patients ont été évalués au regard de l'admissibilité à l'étude, et ce, d'après deux facteurs de risque de reconsultation au SU ( $\geq 1$ consultation au SU au cours de la dernière année et $\geq 6$ médicaments); 132 sujets ont été dirigés au hasard vers le groupe expérimental (GE) et 133 vers le groupe témoin (GT). $L^{\prime}$ intervention consistait en un entretien personnel entre le patient et l'infirmière avant le départ du SU et en deux appels téléphoniques de suivi au cours des 2 semaines suivantes. Le principal critère d'évaluation était le temps écoulé avant une reconsultation au SU au cours des 30 jours suivant le congé. Les critères secondaires d'évaluation comprenaient le temps écoulé avant une reconsultation au SU au cours des 90,180, et 365 jours et avant une hospitalisation au cours des 30, 90, 180, et 365 jours.

Résultats: Une analyse intermédiaire planifiée a révélé que le temps écoulé avant une reconsultation au SU était comparable dans les deux groupes au bout de 30 jours $(p=0.81$; reconsultations: $18.2 \%$ dans le GE contre [c.] 19.6\% dans le GT), de 90 jours $(p=0.44)$, de 180 jours $(p=0.98)$, et de 365 jours ( $p=0.75)$, ce qui a mis fin à l'étude, au moment où la moitié de la taille prévue de l'échantillon avait été atteinte. La seule différence observée était une diminution de la proportion des hospitalisations au bout de 180 jours dans le GE (13.6\% v. $24.1 \% ; p=0.038$ ).

Conclusions: Les résultats vont dans le même sens que ceux d'autres études, selon lesquels peu d'interventions réalisées au SU permettent de réduire le nombre de reconsultations à ce même service. Des facteurs différents de ceux ciblés par l'intervention, notamment une amélioration des soins courants, pourraient expliquer ces résultats.

Keywords: cardiac diseases, emergency department, nursing intervention, randomized controlled trial

From the *Faculty of Nursing, University of Montreal, and Montreal Heart Institute Research Center; tEmergency Department, Montreal Heart Institute; łFaculty of Psychiatry and Nursing, McGill University, and Centre hospitalier de I'Université de Montréal, and Montreal Heart Institute Research Center; §Department of Epidemiology, Biostatistics, and Occupational Health, McGill University, and St. Mary's Research Centre; and \|Department of Biostatistics, Montreal Health Innovations Coordinating Center, Montreal, QC.

Correspondence to: Dr. Sylvie Cossette, University of Montreal, Montreal Heart Institute Research Center, S-2510, 5000, Bélanger est, Montreal, QC H1T 1C8; Sylvie.cossette.inf@umontreal.ca.

This article has been peer reviewed.

(c) Canadian Association of Emergency Physicians 
Emergency department (ED) revisits are a major concern in health care systems across Canada and around the world. ${ }^{1}$ ED revisits contribute to overcrowding, increased waiting times, and impaired quality and safety of care to those in urgent need. Administrative data at the Montreal Heart Institute (2003-2004) revealed that among 10,000 annual patients, $24 \%$ visited the ED more than once during a year, with some making as many as 15 visits. The objective of the current project was to evaluate a nursing intervention designed to reduce ED revisits in a tertiary cardiac hospital.

The published literature is inconclusive regarding the efficacy of interventions aimed at reducing ED revisits, both in Canada and elsewhere. In Canada, only two randomized controlled trials (RCTs) have been published, both in seniors and both with negative results. ${ }^{2,3}$ Among the five non-Canadian RCTs, only one showed a significant reduction in ED revisits in frequent ED users. ${ }^{4}$ Three others did not significantly reduce ED revisits, ${ }^{5-7}$ and one showed a nonsignificant trend toward an increase. ${ }^{8}$ Based on the available literature, we developed a short-term intervention involving telephone follow-up.

The goal of this study was to evaluate the efficacy of the transit-ED nursing intervention compared to usual care in reducing ED revisits among patients discharged home from the ED of a tertiary cardiac hospital who were at high risk for an ED return visit within 30 days.

\section{METHODS}

\section{Study design}

An RCT was conducted to test the hypothesis that patients in the experimental group would be less likely to revisit the ED within 30 days of discharge from an index ED visit. The trial is registered at ISRCTN88422298. ${ }^{9}$

\section{Setting and participants}

The study was conducted in adult patients who visited the ED of a tertiary cardiac hospital in Montreal, Quebec. Consolidated Standards of Reporting Trials (CONSORT) guidelines were followed throughout the study. ${ }^{10,11}$ After explanation of the study in the ED by the project nurse, each participant signed a written consent form before entering the study.

\section{Eligibility criteria}

To be eligible, patients who were ready for discharge from the ED had to be at risk for ED return based on two criteria previously reported ${ }^{12}$ : at least one previous $\mathrm{ED}$ visit in the past year in addition to the index visit and current treatment with at least six different medications (including as needed nitroglycerine). Exclusion criteria included being transferred to a care facility instead of discharged home, inability to speak French or English, life-threatening illness, and cognitive problems precluding providing informed consent specifically noted in the medical chart (e.g., dementia) or based on the clinical judgment of the project nurse. To avoid multiple interveners for the same patient, we also excluded patients already receiving other regular follow-up (e.g., at a specialized clinic in the hospital or provided by external resources).

\section{Interventions}

Patients in both groups received usual care from their regular bedside nurse until the ED medical discharge signature was obtained. All patients were encouraged to contact regular health care resources, such as telephone health hotlines, family physicians or cardiologists, or emergency services as needed. Once the usual care procedure was completed, the project nurse started the intervention for those in the experimental group.

The intervention was based on Ashton and Wray's proposition that to avoid unscheduled revisits, clinical stability should be ensured prior to ED discharge, and patients should be prepared to cope with potential postdischarge concerns. ${ }^{13}$ Using a 19-item disease management risk scale developed in previous studies, ${ }^{3,14-16}$ the project nurse evaluated and intervened on potential illness-, treatment-, or life-related sources of concern after discharge. The intervention was tailored for each patient's specific concerns and included three encounters: one at discharge and two telephone followups at 2 to 4 days and 7 to 10 days postdischarge.

\section{Measures}

Data on ED visits were extracted from a computerized hospital database of all ED and hospital visits (MAGIC software, version 5.1, MédiaMed Technologies, MontSaint-Hilaire, QC) and were analyzed by an independent 
statistician at the Montreal Health Innovations Coordinating Center (MHICC) (http://www.mhicc. org/). Extracted data included medical diagnoses recorded by predetermined codes, the time, and the duration of each visit. There were no missing data on ED revisits. Baseline sociodemographics and clinical variables were obtained from medical charts or were selfreported.

\section{Sample size}

The sample size was based on the time to the first ED revisit. The estimated revisit rate among the targeted at-risk population ( $\geq 1$ previous $\mathrm{ED}$ visit in the past year and six different medications) was $23 \%$ based on ED administrative data (2003-2004) and the literature. We sought to reduce this return rate to $14 \%$, for an absolute reduction of $9 \%$ based on the observed rates of reduction in the literature, ranging from 3.2 to $16 \% .{ }^{17-21}$ To detect such a decrease with a log-rank test, the target sample was set at 231 patients per group $(n=462)$, with $80 \%$ power and two-sided alpha of 0.05 . Because of the large sample, an interim analysis was planned midway through recruitment and was performed by an independent committee of three experts in the fields of ED service use, geriatric care, and cardiac care. An independent statistician from the MHICC carried out the analyses, and the results were transmitted to the steering committee, which then provided recommendations to the research team.

\section{Randomization and blinding}

An independent statistician at the MHICC generated the random allocation sequence (using the PROC PLAN procedure in $S A S$, SAS Institute, Cary, NC) and prepared opaque envelopes containing randomization assignments. The project nurse opened the envelope after obtaining patient consent.

\section{Statistical methods}

Sociodemographic and clinical variables were summarized as mean $\pm \mathrm{SD}$ for continuous variables and as count and percentage for categorical variables. As recommended by the CONSORT statement, ${ }^{22}$ no statistical tests were performed to evaluate baseline differences between groups. The primary end point (time to first nonplanned revisit within the month following randomization) was compared between experimental and control groups using a log-rank test for survival analysis. Patients who did not return to the ED within 1 month following their first discharge were censored at 30 days postrandomization. The time to first $\mathrm{ED}$ revisit within 90, 180, and 365 days and the time to hospitalization within $30,90,180$, and 365 days postrandomization were analyzed similarly. The analysis was conducted according to the intention-to-treat principle and used all randomized patients. Statistical analyses for the primary and secondary end points were performed using $S A S$ version 9.2.

\section{Exploratory analyses}

Two exploratory sets of analyses were performed after the results of the planned analysis were completed. First, the group patterns of ED revisits were compared after the first telephone call at 4 days postdischarge and after the last telephone call at 19 days postdischarge. For these analyses, we used the same analytic strategy as for the originally planned analyses. Second, we used two classifications to examine whether or not the ED revisits were avoidable, recognizing the limit of these proxy indicators. First, ED revisits resulting in patients being discharged home were classified as avoidable and those resulting in patients being hospitalized were classified as unavoidable. ${ }^{23}$ Second, we examined whether the ED revisits occurred for the same or different health problems as the index visit. ${ }^{24,25}$ Returning ED revisits for the continuation or worsening of the same health problem were classified as avoidable, and those for a different health problem were classified as unavoidable. Classification of the reasons for revisits was performed by one of the investigators (A.V.) blinded to study group assignment.

\section{Ethics}

The study was reviewed and approved by the Research Ethics Board of the hospital, and informed written consent was obtained from all subjects.

\section{RESULTS}

\section{Interim analysis results}

The midstudy recruitment target of 231 was reached in January 2010, but recruitment continued until the 
interim analysis ${ }^{26}$ was completed. In March 2010, early termination of the study was recommended by the steering committee based on the small possibility of a change in the trajectory of results. Recruitment was stopped on March 30, 2010.

\section{Participant flow}

A total of 3,785 patients were evaluated between November 13, 2006, and March 30, 2010 (Figure 1). Among the 3,530 patients excluded, 2,359 did not meet the study criteria, 825 had logistical issues (e.g., discharge hours), and 346 refused to participate, resulting in 265 patients randomized.

\section{Sample description}

Baseline and ED characteristics were similar in the experimental and control groups (Table 1, Table 2, and Table 3). The most common emergency triage scores were 3 (urgent) and 4 (less urgent), reflecting the inclusion criterion requiring patients to be discharged home.

\section{Intervention description}

All but one of the intervention patients participated in the first face-to-face encounter before returning home, whereas 121 (92\%) and 126 (95\%) patients participated in the first and second telephone follow-ups, respectively (see Figure 1). The mean durations for each of the three nursing interventions were 13, 22, and 18 minutes, for a mean total of 43 minutes.

\section{Hypothesis testing}

\section{Primary outcome}

There was no significant difference between the groups in the time to first ED revisit over 30 days (Table 4).

\section{Planned secondary outcomes}

There was no significant difference between the groups in the time to first ED revisit over 90, 180, or 365 days or in the time to hospitalization at the index hospital over 30,90 , or 365 days after the initial visit; however, there was a significant difference in the time to hospitalization over 180 days in the experimental group versus the control group group (see Table 4).

\section{Exploratory analysis}

At 4 and 19 days (following each nursing telephone call), similar patterns regarding ED return were observed as the planned analyses, with no evidence of a significant effect of the group on the time to ED revisits.

The two strategies for classifying avoidable versus unavoidable ED revisits yielded parallel results. By 30 days, 22 experimental and 21 control patients revisited the ED but were discharged home $(p=0.85)$. Thirteen patients from the experimental group revisited for the index diagnosis or for an associated problem compared to 16 from the control group $(p=0.60)$. This pattern was similar for the other time points. Small cell numbers precluded analyses at 4 days.

\section{DISCUSSION}

This large RCT was designed to evaluate the effect of a nursing intervention on ED revisits at 30 days postdischarge in patients who were frequent ED visitors. Despite up to three interactions with a nurse counselor, personalized approaches, and a large sample, this study was stopped early due to futility, and the intervention was shown to be ineffective. The sole difference found on time to hospitalization over 180 days is likely due to chance given the absence of other differences in service use, being a secondary outcome, and the number of statistical tests performed. The lack of difference observed in the present study is consistent with most previous RCTs. ${ }^{2,3,5-8}$

Although we attempted to distinguish between avoidable and nonavoidable ED revisits using two definitions from the literature, ${ }^{23-25}$ we still found no evidence of study impact. The avoidability of visits is a subjective evaluation combining clinical indicators and patient-professional interactions during the ED visit and may not be recorded in the hospital chart, making it difficult to determine reliably whether preventive actions might have been possible or effective.

The intervention was designed to be flexible, and it focused on ED avoidance and was compared to standard of care in the study hospital. It is possible, however, that contamination between groups occurred despite efforts to "isolate" the project nurse and participants during the first encounter in the ED. It is also possible that the experimental condition was too similar to usual care at this ED. A previous study showed medication to be a strong predictor of ED return, ${ }^{12}$ and during this study, a full-time pharmacist 


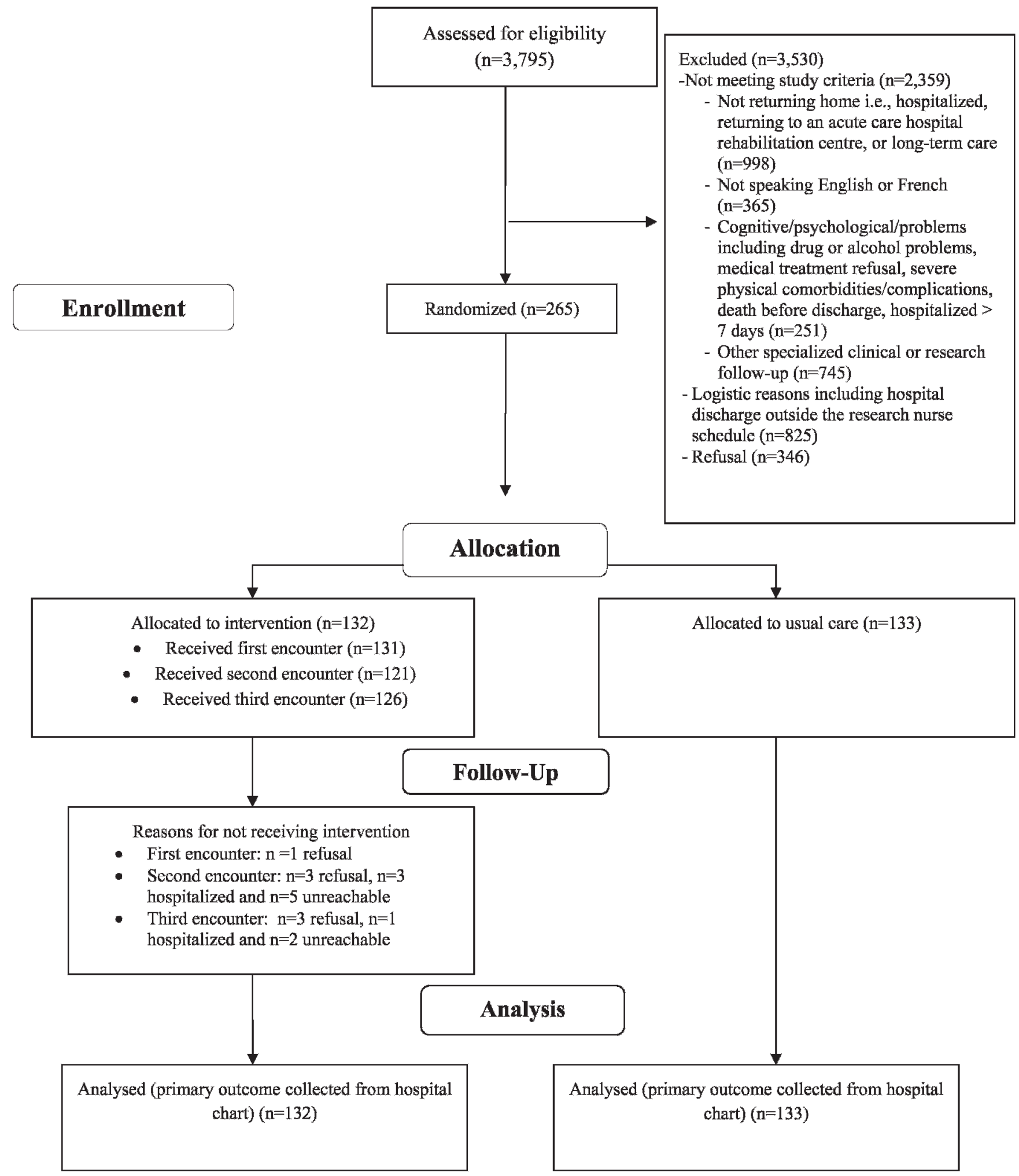

Figure 1. Consolidated Standards of Reporting Trials (CONSORT) flow diagram for the transit-ED clinical trial. 


\begin{tabular}{|c|c|c|}
\hline Characteristic & Experimental $(n=132)$ & Control $(n=133)$ \\
\hline \multicolumn{3}{|l|}{ Age (yr) } \\
\hline Mean \pm SD & $67.02 \pm 10.5$ & $67.39 \pm 9.9$ \\
\hline$\geq 65 \mathrm{yr}, n(\%)$ & $85(64.4)$ & $82(61.7)$ \\
\hline Sex (male), $n(\%)$ & 77 (58.3) & $72(54.1)$ \\
\hline Working $(n=260), n(\%)$ & $28(21.2)$ & $29(21.8)$ \\
\hline Education ( $\leq$ high school) $(n=256), n(\%)$ & $76(57.6)$ & $68(51.1)$ \\
\hline Married $(n=261), n(\%)$ & $77(58.3)$ & $81(61.0)$ \\
\hline Lives alone $(n=261), n(\%)$ & $40(30.3)$ & $33(24.8)$ \\
\hline Drives a car $(n=233), n(\%)$ & $88(66.6)$ & 89 (66.9) \\
\hline Lives on Montreal Island, $n(\%)$ & $93(70.5)$ & $94(70.7)$ \\
\hline Has a family physician $(n=264), n(\%)$ & $121(91.7)$ & 119 (89.5) \\
\hline
\end{tabular}

began providing predischarge verification of medication for all patients. The impact of the study intervention directed at helping patients with their medications may have been diluted by this other intervention.

\section{Study limitations and strengths}

This study has several limitations. The generalizability of the study results to the ED population may be limited because the study hospital was a tertiary cardiac centre with a cardiac specialty ED, although many patients did not have a cardiac diagnosis at discharge. Given that our study's inclusion criteria required at least one ED visit in the previous year, it is possible that the most appropriate response to a recurrence was to revisit the ED where patients had received their initial evaluation and treatment, thereby avoiding preliminary evaluations that would be necessary at a new health care facility. Finally, we analyzed ED returns only at the study hospital. Future analysis of this trial will include examination of the provincial database to identify medical interventions and services used elsewhere.

Despite the aforementioned limitations, several methodological strengths of this study should be mentioned. First, the study was performed using allocation concealment, blinding of the analysis, and complete reporting of patient-oriented and clinically meaningful outcomes. Second, due to the outcome measures, there were limited missing data. Finally, although interim analyses are considered controversial, the results from the midterm analysis were sent to an

\begin{tabular}{|lcc|}
\hline Table 2. Baseline clinical characteristics of $\mathbf{2 6 5}$ high-risk patients discharged from a tertiary care cardiac ED \\
\hline Discharge diagnosis & Experimental $(n=132) n(\%)$ & Control $(n=133) n(\%)$ \\
\hline Cardiac related (any) & $95(72.0)$ & $95(71.4)$ \\
Chest pain (stable angina, atypical chest pain, eliminate unstable angina) & $33(25.0)$ & $33(25.0)$ \\
Any arrhythmia & $32(24.2)$ & $38(28.6)$ \\
Heart failure & $13(9.8)$ & $10(7.5)$ \\
Hypertension & $7(5.3)$ & $2(1.5)$ \\
Postprocedure complications (e.g., hematoma, pleural effusion) & $4(3.0)$ & $5(3.8)$ \\
Problems related to medications & $3(2.3)$ & $4(3.0)$ \\
Vascular & $3(2.3)$ & $3(2.3)$ \\
Non-cardiac related (any) & $37(28.0)$ & $38(28.6)$ \\
COPD, asthma, or pneumonia & $5(3.8)$ & $5(3.8)$ \\
Gastrointestinal (e.g., dyspepsia, gastroesophageal reflux) & $4(3.0)$ & $4(3.0)$ \\
Psychological (e.g., anxiety, depression) & $3(2.3)$ & $5(3.8)$ \\
Other symptoms (e.g., dyspnea, lipothymia, anemia, falls, cold, cough) & $25(18.9)$ & $24(18.0)$ \\
\hline COPD = chronic obstructive pulmonary disease; ED = emergency department. &
\end{tabular}




\begin{tabular}{|c|c|c|}
\hline Characteristic & Experimental $(n=132)$ & Control $(n=133)$ \\
\hline Transportation to index visit by ambulance (v. other transportation), $n(\%)$ & $29(22.0)$ & $15(11.3)$ \\
\hline \multicolumn{3}{|l|}{ Triage score } \\
\hline Resuscitation (1) & 0 & 0 \\
\hline Emergent (2) & $5(3.8)$ & $7(5.3)$ \\
\hline Urgent (3) & $60(45.5)$ & $66(49.6)$ \\
\hline Less urgent (4) & $60(45.5)$ & $56(42.1)$ \\
\hline Nonurgent (5) & $7(5.3)$ & $4(3.0)$ \\
\hline On stretcher (v. ambulatory), $n(\%)$ & $95(72.0)$ & $87(65.4)$ \\
\hline Visit to ED with someone (v. no), $n(\%)$ & $66(50.0)$ & $53(39.8)$ \\
\hline Brought from home (v. elsewhere) $(n=250), n(\%)$ & $111(91.0)$ & $117(91.4)$ \\
\hline Number of medications on arrival at ED (range 6-24), mean \pm SD & $9.22 \pm 2.72$ & $9.96 \pm 3.68$ \\
\hline \multicolumn{3}{|l|}{ Change of medication at discharge, $n(\%)$} \\
\hline No change (v. any change) & $50(37.9)$ & $48(36.1)$ \\
\hline Dosage change (v. no dosage change) & $40(30.3)$ & $44(33.1)$ \\
\hline Medication added (v. no addition) & $61(46.2)$ & $53(39.8)$ \\
\hline Medication withdrawn (v. not withdrawn) & $27(20.5)$ & $23(17.3)$ \\
\hline \multicolumn{3}{|l|}{ External referrals at discharge, $n(\%)$} \\
\hline To family physician (v. no) & $20(15.2)$ & $25(18.8)$ \\
\hline Any other reference (MD specialist, laboratory, or test [Holter, MIBI]) (v. no) & 79 (59.8) & $75(56.4)$ \\
\hline Mean \pm SD number of hours in ED (from entry to discharge) & $19.04 \pm 15.73$ & $19.91 \pm 17.19$ \\
\hline
\end{tabular}

independent advisory committee for decision. We believe that these results are valid and robust.

\section{CONCLUSION}

As in several previous studies aiming to decrease ED overuse, the present RCT was unable to demonstrate a reduction in ED revisits following a nurse-initiated intervention designed to reduce or avoid ED presentations in patients with frequent ED use. The results add to the literature by examining the timing of ED revisits and reasons for return visits, providing further evidence on this complex issue. Searching for continuity of care may explain why patients choose to revisit the initial $\mathrm{ED}$, whether for a continuation of their previous problem or for a different one.

Table 4. Effect of the intervention on ED revisits and hospitalizations for $\mathbf{2 6 5}$ high-risk patients discharged from a tertiary care cardiac ED

\begin{tabular}{|c|c|c|c|}
\hline & Experimental $(n=132) n(\%)$ & Control $(n=133) n(\%)$ & Log-rank $p$ value for group \\
\hline \multicolumn{4}{|c|}{ Primary outcome } \\
\hline ED 30 days & $24(18.2)$ & $26(19.6)$ & 0.81 \\
\hline \multicolumn{4}{|c|}{ Secondary outcomes } \\
\hline \multicolumn{4}{|c|}{ ED } \\
\hline 90 days & $51(38.6)$ & $44(33.1)$ & 0.44 \\
\hline 180 days & $61(46.2)$ & $62(46.6)$ & 0.98 \\
\hline 365 days & $72(54.6)$ & $76(57.1)$ & 0.75 \\
\hline \multicolumn{4}{|c|}{ Hospitalization } \\
\hline 30 days & $8(6.1)$ & $4(3.0)$ & 0.24 \\
\hline 90 days & $13(9.9)$ & $19(14.3)$ & 0.31 \\
\hline 180 days & $18(13.6)$ & $32(24.1)$ & 0.038 \\
\hline 365 days & $25(18.9)$ & $38(28.6)$ & 0.068 \\
\hline
\end{tabular}


Acknowledgements: We thank the patients who generously agreed to participate. We also thank the nurses, including Francois Pilon, RN, BSc, Johanne Vezina, RN, BSc, and Johane Loyer, RN, BSc, as well as the director of nursing who supported the project (Marie-Hélène Carbonneau, RN, MSc). We thank the members of the interim analysis committee, Drs. Marc Afilalo, Danielle Roberge, and Jacques Lelorier.

Competing interests: Funding was obtained from the Fonds de la recherche en santé du Québec (FRSQ), the Quebec Interuniversity Nursing Intervention Research Group (GRIISIQ), and the Montreal Heart Institute Foundation and Research Center. Writing and editing consultation was provided by Kate Johnson, BA, BJ.

\section{REFERENCES}

1. Understanding emergency department wait times. III. Who is using emergency department and how long are they waiting?. Ottawa (ON): Canadian Institute of Health Information; 2005.

2. Gagnon A, Schein C, McVey LN, et al. Randomized controlled trial of nurse case management of frail older people. 7 Am Geriatr Soc 1999;47:1118-24.

3. McCusker J, Jacobs P, Dendukuri N, et al. Cost-effectiveness of a brief two-stage emergency department intervention for high-risk elders: results of a quasi-randomized controlled trial. Ann Emerg Med 2003;41:45-56, doi:10.1067/mem.2003.4.

4. Shumway M, Boccellari A, O'Brien K, et al. Cost-effectiveness of clinical case management for ED frequent users: results of a randomized trial. Am 7 Emerg Med 2008;26:15564, doi:10.1016/j.ajem.2007.04.021.

5. Hansagi $\mathrm{H}$, Olsson $\mathrm{M}$, Hussain $\mathrm{A}$, et al. Is information sharing between the emergency department and primary care useful to the care of frequent emergency department users? Eur 7 Emerg Med 2008;15:34-9, doi:10.1097/MEJ.0b013e3282aa4115.

6. Spillane LL, Lumb EW, Cobaugh DJ, et al. Frequent users of the emergency department: can we intervene? Acad Emerg Med 1997;4:574-80, doi:10.1111/j.1553-2712.1997.tb03581.x.

7. Caplan GA, Williams AJ, Daly B, et al. A randomized, controlled trial of comprehensive geriatric assessment and multidisciplinary intervention after discharge of elderly from the emergency department--the DEED II study. $7 \mathrm{Am}$ Geriatr Soc 2004;52:1417-23, doi:10.1111/j.1532-5415.2004. 52401.x.

8. Mion LC, Palmer RM, Meldon SW. Case finding and referral model for emergency department elders: a randomized clnical trial. Ann Emerg Med 2003;41:57-68, doi:10. 1067/mem.2003.3.

9. Current Controlled Trials. Available at: www.controlled-trials. com (accessed April 19, 2013).

10. Zwarenstein $M$, Treweek S, Gagnier JJ, et al. Improving the reporting of pragmatic trials: an extension of the CONSORT statement. BM7 2008;337(a2390):1-8, doi:10.1136/bmj.a2390.

11. The Consort Group. The Consort Statement. Available at: http://www.consort-statement.org/ (accessed April 19, 2013).

12. Vadeboncoeur A, Kennedy W, Bourdages T, et al. Risk factor predicting return to the emergency department by patients using the emergency department of the Montreal Heart Institute. Poster presentation at the 2nd Mediterranean Emergency Medicine Congress 2003; Barcelona, Spain. Available at: http://www. emcongress.org/barcelona03/ (accessed August 5, 2013).

13. Ashton CM, Wray NP. A conceptual framework for the study of early readmission as an indicator of quality of care. Soc Sci Med 1996;43:1533-41, doi:10.1016/S0277-9536(96) 00049-4.

14. Heppell S, Cossette S, Vadeboncoeur A, et al. Exploration of needs for follow-up among patients after an emergency department visit: a focus group investigation [Identification des besoins de suivi chez des patients qui se présentent dans une urgence cardiologique: résultats d'un focus groupe]. Can 7 Cardiovasc Nurs 2005;15(1):50.

15. Cossette S, Frasure-Smith N, Lespérance F. Clinical implications of a reduction in psychological distress on cardiac prognosis in patients participating in a psychosocial intervention program. Psychosom Med 2001;63:257-66.

16. Frasure-Smith N, Lespérance F, Prince RH, et al. Randomised trial of home-based psychosocial nursing intervention for patients recovering from myocardial infarction. Lancet 1997; 350:473-9, doi:10.1016/S0140-6736(97)02142-9.

17. Hegney D, Buikstra E, Chamberlain C, et al. Nurse discharge planning in the emergency department: a Toowoomba, Australia, study. 7 Clin Nurs 2006;15:103344, doi:10.1111/j.1365-2702.2006.01405.x.

18. Miller DK, Lewis LM, Nork MJ, et al. Controlled trial of a geriatric case-finding and liaison service in an emergency department. 7 Am Geriatr Soc 1996;44:513-20.

19. Andren KG, Rosenqvist U. Heavy users of an emergency department: psycho-social and medical characteristics, other health care contacts and the effect of a hospital social worker intervention. Soc Sci Med 1985;21:761-70, doi:10.1016/02779536(85)90124-8.

20. Okin RL, Boccellari A, Azocar F, et al. The effects of clinical case management on hospital service use among ED frequent users. Am 7 Emerg Med 2000;18:603-8, doi:10. 1053/ajem.2000.9292.

21. Guttman A, Afilalo M, Guttman R, et al. An emergency department-based nurse discharge coordinator for elder patients: does it make a difference? Acad Emerg Med 2004;11: 1318-27, doi:10.1197/j.aem.2004.07.006.

22. Moher D, Hopewell S, Schulz KF, et al. CONSORT 2010 explanation and elaboration: updated guidelines for reporting parallel group randomised trials. $\mathcal{F}$ Clin Epidemiol 2010; 63(8):e1-37, doi:10.1016/j.jclinepi.2010.03.004.

23. McCusker JM, Ionescu-Ittu R, Ciampi A, et al. Hospital characteristics and emergency department care of older patients are associated with return visits. Acad Emerg Med 2007;14:426-32.

24. Clarke A. Are readmissions avoidable? BMf 2004;301:11368, doi:10.1136/bmj.301.6761.1136.

25. Cardin S, Affilalo M, Lang E, et al. Intervention to decrease emergency department crowding: does it have an effect on return visits and hospital readmissions. Ann Emerg Med 2003;41:173-85, doi:10.1067/mem.2003.50.

26. Snapinn S, Chen M-G, Jiang Q, et al. Assessment of futility in clinical trials. Pharm Stat 2006;5:273-81, doi:10.1002/ pst.216. 